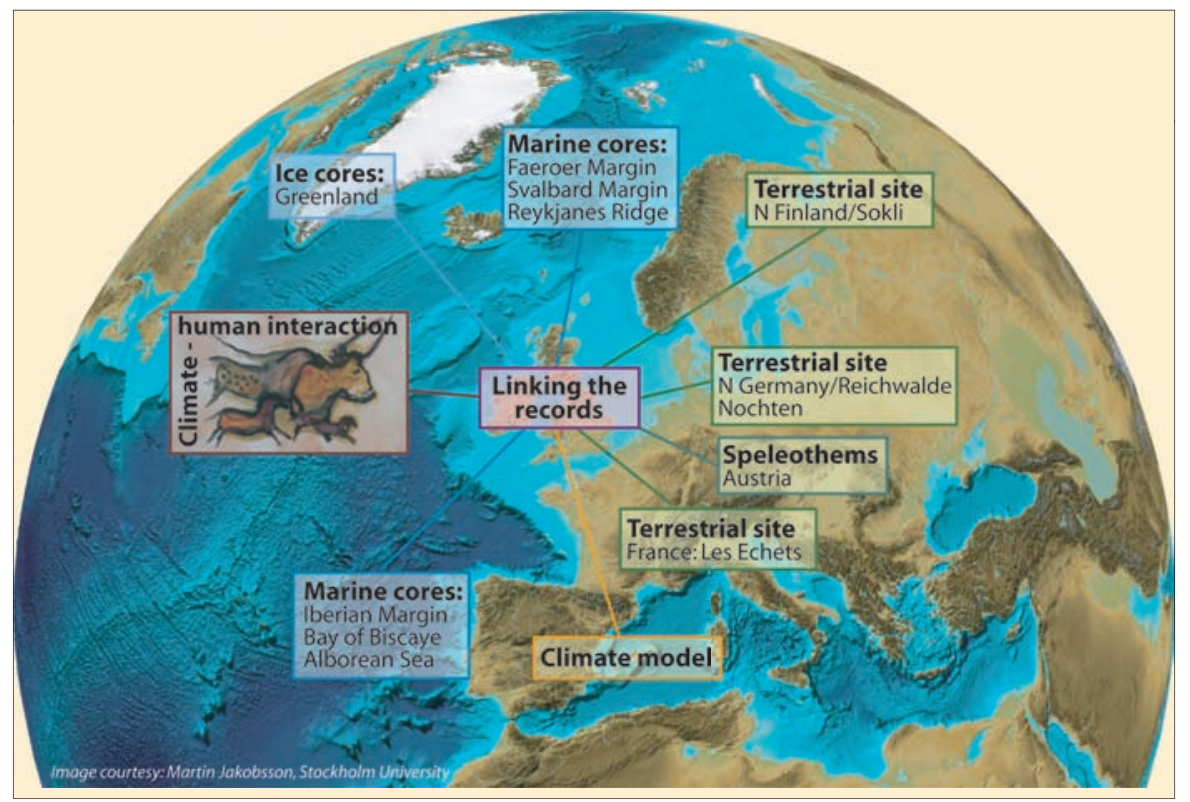

Figure 1: The different sites of the RESOLUTION network project.

sons the GICC05 chronology back to $42 \mathrm{kyr}$ BP (Andersen et al., 2006) and the GRIPss09 chronology back to $60 \mathrm{kyr}$ BP (Johnsen et al., 2001). All ${ }^{14} \mathrm{C}$ dated sequences are wiggle-matched against the comparison curve of Hughen et al. (2006), until the new IntCal calibration curve is released.
Transient simulations with a coupled atwill finally be compared with the data sets emerging from the land and ocean sites.

RESOLUTION started in January 2005 and will end in December 2008. Financial support for the project is provided by research councils in Sweden, Denmark, The Netherlands and France and has enabled the recruitment of PhD students and postdoctoral researchers. The next workshop (1-4 October, 2007) will be organized in The Netherlands. Please contact Barbara Wohlfarth (Barbara@geo.su.se) for enquiries about RESOLUTION and Hans Renssen (hans.renssen@geo.falw.vu.nl) regarding the upcoming workshop.

\section{References}

Andersen, K.K., Svensson, A., Johnsen, S.J., Rasmussen, S.O., Bigler, M., Röthlisberger, R., Ruth, U., Siggaard-Andersen, M-L., Steffensen, J.P., Dahl-Jensen, D., Vinther, B.M., and Clausen, H.B., 2006: The Greenland Ice Core Chronology 2005, 15-42 ka. Part 1: constructing the time scale, Quaternary Science Reviews, 25: 3246-3257.

Hughen, K.A., Southon, J.A., Lehman, S.J., Bertrand, C.J.H., and Turnbull, J., 2006: Marine-derived ${ }^{14} \mathrm{C}$ calibration and activity record for the past 50,000 years updated from the Cariaco Basin, Quaternary Science Reviews, 25: 3216-3227.

Johnsen, S.J., Dahl-Jensen, D., Gundestrup, N., Steffensen, J.P., Clausen, H.B., Miller, H., Masson-Delmotte, V., Sveinbjörnsdottir, A.E., and White, J., 2001: Oxygen isotope and palaeotemperature records from six Greenland ice-core stations: Camp Century, Dye-3, GRIP, GISP2, Renland and NorthGRIP, Journal of Quaternary Sciences, 16: 299-307.

\title{
Past Human-Climate-Ecosystem Interactions (PHAROS)
}

John Dearing ${ }^{1}$ and Rick Battarbee ${ }^{2}$

'Department of Geography, University of Liverpool, UK.; j.dearing@liverpool.ac.uk Environmental Change Research Centre, University College London, UK; ufcabat@ucl.ac.uk

\section{Introduction}

The Focus 4 PHAROS theme addresses interactions between climate, ecological processes, and human activities in the past in order to understand better the behavior of ecological systems in the present and future (Oldfield and Dearing, 2003; Dearing et al., 2006a,b). It seeks to address three key gaps in scientific knowledge. First, complex relationships between climate, environment and human activities lie at the heart of modern ecological concerns, yet the longer-term context for these relationships are often poorly understood (cf. Dearing, 2006). These include: the role of spatial scale in determining the nature of interactions; the impacts of multiple stressors on ecosystems through time; and the direct effects of human activities on the earth/climate system as opposed to the cumulative indirect effects of local impacts. Second, the response of ecosystems and associated ecological processes to rapid rates of climate change, with and

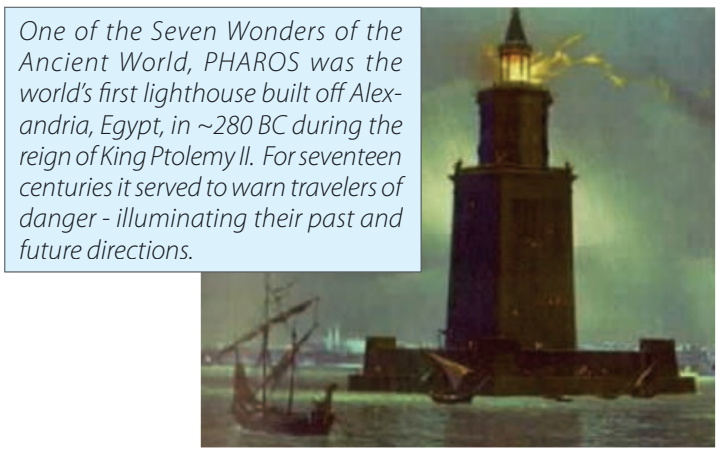

without changing human activities, requires urgent attention. This is particularly the case for ecosystems that are known to be highly sensitive to climate change (IPCC 2001; 2007 forthcoming), or where model projections indicate regions of very rapid climate change in future (e.g., Giorgi, 2006; Williams et al., 2007). Third, the past and current status of key ecological resources and processes is incomplete for many regions. There are no comprehensive reviews of changing hydrology and hydrobiology, soil and land-cover, or disturbance regimes over decadal-to-millennial time scales. This information is vital in assessing the current status of ecosystem services, developing sustainable management strategies, and for testing the current generation of climate and carbon models, Dynamic Global Vegetation Models (DVGM's), and impactassessment models (Prentice et al., 1992; Sellers et al., 1997; Battarbee et al., 2005; Anderson et al., 2006). An important ele- ment in PHAROS is a new working group, INTEMODS, tasked with promoting integration between case-studies, producing regional/global syntheses and developing modeling tools.

\section{Theme Goals}

PHAROS seeks to understand ecosystem change on different time scales and at spatial scales ranging from local to global. For any specified ecosystem the following generic questions are posed:

- What is the nature of human activities that have influenced and are influencing modern ecological systems? For example, what are the historic links between irrigation and flood regime under different environmental conditions?

- How have these human activities interacted with climate processes through feedbacks? For example, at what spatial 


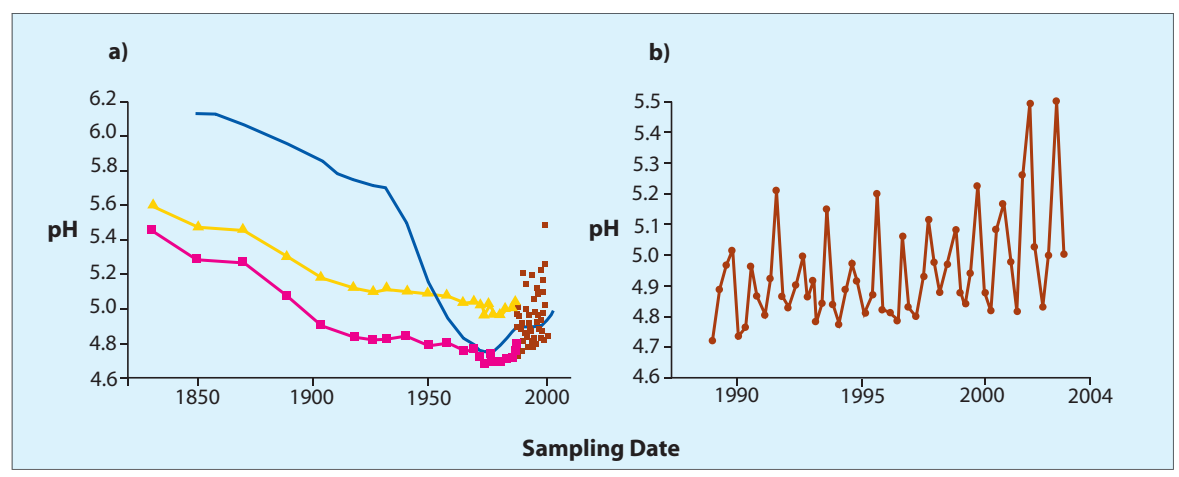

Figure 1: Comparative pH trends at the Round Loch of Glenhead, Galloway, SW Scotland. a) diatom-inferred lakewater $\mathrm{pH}$ (yellow triangles and pink squares, estimates derived from two different transfer functions) was compared with $\mathrm{pH}$ values from the MAGIC model of catchment acidification (blue line) and contemporary monitoring data (red squares). Both approaches indicate that the lake has acidified over the past 150years, although there are clear differences between the estimated pH of the lake during the mid-19th century $\boldsymbol{b}$ ). There is considerable inter-and intra-annual variability in monitored $\mathrm{pH}$ values at the site but the upward trend in response to reductions in acid deposition is clear (Data from Battarbee et al., 2005; figure re-drawn from Anderson et al., 2006).

scale has European deforestation affected climate - local, regional, global? What are the consequences of large-scale biomass burning?

- How have human and climate impacts interacted with internal system dynamics? For example, to what extent are river channel changes a consequence of external or internal forces, such as land use, climate, hydraulic dynamics, or system configuration?

- How sensitive or resilient are modern ecological systems to new or increased stresses from human activities and climate? Which ecological processes have been the most responsive to past rapid climate change? Which will be sensitive to future projections? In this sense, Figure 1 shows the value of long-term reconstructions of lake $\mathrm{pH}$ against which to compare mathematical models of acidification and recent monitored records of water quality.

- What are the appropriate sustainable management strategies? For example, what is the historical range of variability in natural disturbance regimes, what reference conditions are most relevant for ecosystem restoration or which land use is the most appropriate in the face of projected change? Figure 2 shows a selection of environmental proxies for the last 3,000 years in the Lake Erhai catchment in Yunnan, China, which provide the basis for examining long-term links between climate, human activities and geomorphological responses - and hence system resilience and sustainability.

\section{Approaches, Implementation Strategy and Links}

The proposed structure of PHAROS (Fig. 3) takes into account the above science gaps, questions, issues and methods, the organization of existing communities, links to new PAGES Cross-Cutting Themes, links to other IGBP Core Projects (e.g., AIMES) and links to new ESSP cross-cutting international programs (e.g., IHOPE). PHAROS retains the three previously defined Focus 5 pro- grams, HITE, LUCIFS and LIMPACS, which have successful national and international identities. In PHAROS, these Activities have slightly modified names that capture better the new emphasis on interactions. The proposed priorities until 2009 address major science gaps: Climate Hotspots, Water, Soil, and Land cover. Within each Activity there are links to the PAGES Cross-Cutting Themes 1-4. INTEMODS represents the key link to other IGBP and related projects, particularly AIMES and IHOPE.

\section{Activities and Products \\ Activity 1: INTEMODS - Integration and Modeling of Past Human-Climate- Ecosystem Interactions.}

The main functions of INTEMODS are to provide global syntheses of paleodata, promote regional syntheses of past humanclimate-ecosystem interactions, provide historical environmental diagnoses/profiling of key systems and provide the focus for developing new predictive modeling approaches, independently and in collaboration with climate and socio-ecosystem modeling groups. INTEMODS defines the milestones and envisaged outputs for the PHAROS program by 2009. Four working groups are proposed: Regional Syntheses-Climate Change Hotspots; Global Syntheses-Water; Global Syntheses-Soil; and Global Syntheses-Land Cover.

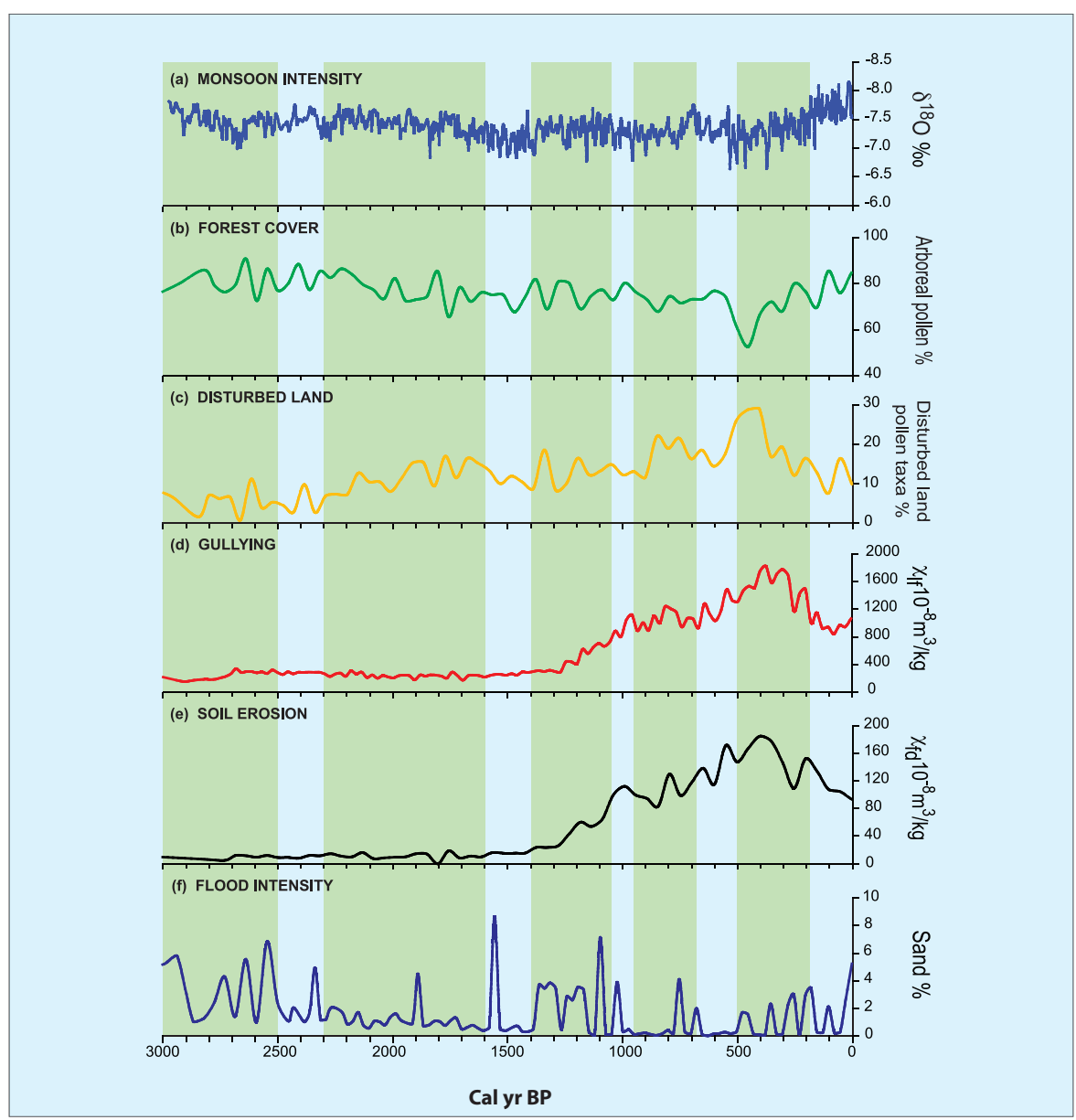

Figure 2: Erhai Lake catchment, Yunnan Province, China-environmental proxies over the past 3,000 years: a) summer monsoon proxy (Dongge Cave speleothem oxygen isotopes) (Wang et al., 2005); b) forest cover (lake sediment total arboreal pollen taxa) (Shen et al., 2006); c) disturbed land (lake sediment disturbed land pollen taxa) (Shen et al., 2006); d) gully erosion (lake sediment magnetic susceptibility) (Shen et al., 2006); e) surface soil erosion (lake sediment frequency dependent magnetic susceptibility) (Dearing et al., in press): f) flood intensity (lake sediment sand fraction) (Shen et al., 2006). Vertical green bars define main periods of human impact on environment from archeological and documentary (Elvin et al., 2002) records: Bronze Age culture; Han irrigation technology; Nanzhao and Dali Kingdoms; the late Ming/early Qing environmental crisis. Analysis of the data allows examination of the major sets of interactions between climate, human activities and geomorphological processes. This provides a basis for understanding the long-term changes in system resilience and the prospects for sustainable management in the modern catchment system (Dearing, in press; Dearing et al., in press). 


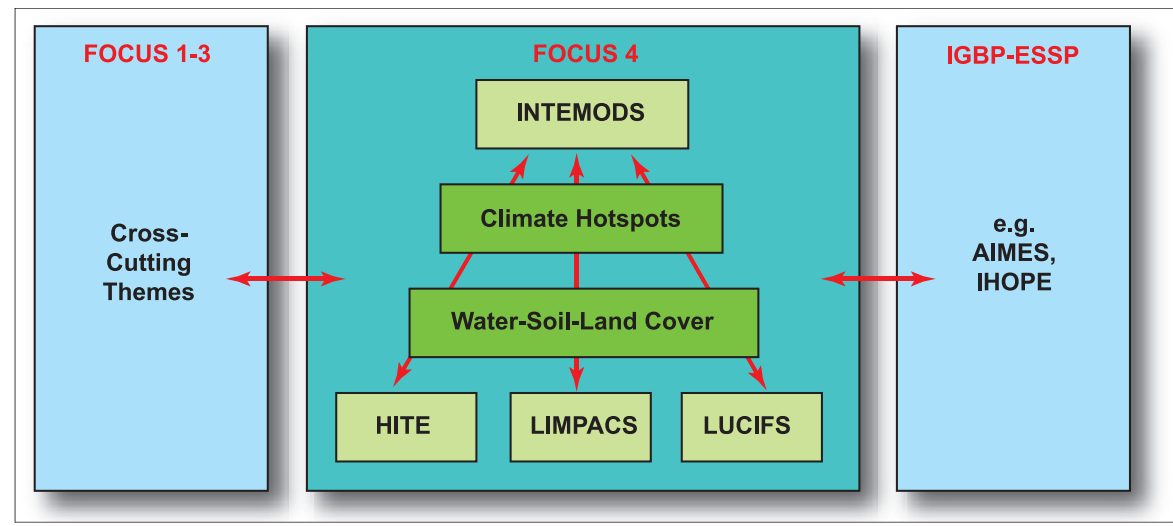

Figure 3: PHAROS Focus 4 structure, links and interactions showing four Activities (INTEMODS, HITE, LIMPACS, LUCIFS), short-term regional-global priorities (Climate Hotspots, Water, Soil and Land Cover), and links to PAGES Cross-Cutting Themes and other IGBP-ESSP programs/projects.

\section{Activity 2: HITE - Human-Climate Interactions with the Terrestrial Environment.}

The HITE Activity is designed to further the study of paleorecords and other ecological archives in documenting and understanding the interactions between human activities and terrestrial ecosystems through time, thereby ensuring the security and services of terrestrial ecosystems for the future. Three working groups cover: New Case-Studies, Regional Syntheses and Land Cover Syntheses (linking closely with POLLANCAL).
Activity 4: LUCIFS - Land Use and Climate Interactions with Fluvial Systems

LUCIFS focuses on a systems-based understanding and analysis of the relationship between the external drivers of land use and climate change on fluvial/sediment processes over timescales that encompass the period of agriculture. Working groups include: Regional and Global Syntheses of Case Studies; Advanced Case Studies; Modeling; and Linking Rivers to the Coast.

\section{References:}

Battarbee, R.W., Monteith. D. Juggins, S. Evans, C. D, Jenkins, A and Simpson, G.L., 2005: Reconstructing pre-acidification pH for an acidified Scottish loch: a comparison of palaeolimnological and modelling approaches, Environmental Pollution, 137: 135-149.

Dearing, J.A., 2006: Climate-human-environment interactions: resolving our past, Climate of the Past, 2: 187-203.

Dearing, J.A., Battarbee, R.W., Dikau, R., Larocque, I. and Oldfield, F., 2006a: Human-environment interactions: towards synthesis and simulation, Regional Environmental Change, 6: 1-16.

Dearing, J.A., Battarbee, R.W., Dikau, R., Larocque, I. and Oldfield, F., 2006b: Human-environment interactions: learning from the past, Regional Environmental Change, 6: 115-123.

Oldfield, F. and Dearing, J.A., 2003: The role of human activities in past environmental change. In: Alverson, K., et al. (Eds), Paleoclimate, Global Change and the Future, IGBP Synthesis Book Series, Springer Verlag, 143-162. Organic Carbon, Salinity, Toxic Pollution, Sediment infilling, and effects of Climate Change.

\title{
Integrated History and future Of People on Earth (IHOPE)
}

\author{
Kathy HibBard ${ }^{1}$ and Robert Costanza ${ }^{2}$ \\ 'National Center for Atmospheric Research, USA; kathyh@ucar.edu \\ Gund Institute for Ecological Economics, University of Vermont, USA; Robert.Costanza@uvm.edu
}

\section{Background and Goals}

Human history has traditionally been cast in terms of the rise and fall of great civilizations, wars, and specific human achievements. This history excludes the important ecological and climate contexts that shaped and mediated these events (Fig. 1). Human history and Earth System science have traditionally been developed independently, with little interaction among the academic communities. Separate methods of describing these histories have, therefore, been developed, and there have been few attempts to integrate these histories and information across these fields of study. Recent recognition that current Earth System changes are strongly associated with the changes in the coupled human-environment system make the integration of human history and Earth System history an important step in understanding the factors leading to global change and in developing strategies for the future.

The goal of the Integrated History and future Of People on Earth (IHOPE) project
(Costanza et al., 2007a) is to understand the interactions of the environmental and human processes over the past several ten to hundred millennia to determine how human and biophysical changes have contributed to Earth System dynamics. In order to reach this goal, our objective is to produce an integrated history of Earth System dynamics, technologies, human and land use systems and many additional variables from new and existing data sources in a spatially and temporally consistent framework.

Human-environment systems are intimately linked in ways that we are only beginning to appreciate (van der Leeuw, 1998; Redman, 1999; Steffen et al., 2004; Diamond, 2005; Kirch, 2005). To achieve the ambitious goals of IHOPE there are multiple scientific challenges that must be met. In order to fully understand the history of the Earth it is necessary to integrate the different perspectives, theories, tools, and knowledge of multiple disciplines across the full spectrum of social and natural sciences and the humanities.
Three major long-term goals have been identified for the IHOPE project:

1. Map the integrated record of biophysical and human system change since time of human settlement, e.g., Australian history might cover up to the last 60,000 years, and in southern Europe, the last 20,000 years would capture initial colonization since the Last Glacial Maximum (LGM).

2. Understand and evaluate the connections and dynamics of humans-in-environment systems' models against an integrated history, e.g., how well do various models of the relationships between climate, agriculture, technology, disease, and other variables explain the historical patterns of human settlement, population, energy use, and biogeochemistry?

3. Project options for the future of humanity and Earth System dynamics based on integrated models and histories. 